\title{
Korean Version of the Thought-Action Fusion Scale: The Evidence for Its Psychometric Properties
}

\author{
Seung Jae Lee ${ }^{1,2 \bowtie}$ and Soonhee Lee ${ }^{3}$ \\ ${ }^{1}$ Department of Psychiatry, School of Medicine, Kyungpook National University, Daegu, Republic of Korea \\ ${ }^{2}$ Department of Psychiatry, Kyungpook National University Hospital, Daegu, Republic of Korea \\ ${ }^{3}$ Counseling Center, University of Maryland, Baltimore County (UMBC), Baltimore, MD, USA
}

\begin{abstract}
Objective The Thought-Action Fusion Scale (TAFS) is a self-reported instrument used to measure a cognitive bias, namely, thoughtaction fusion (TAF), in which intrusive thoughts have moral and actual consequences. The aim of this study is to investigate the reliability and validity of the Korean version of the 19-item TAFS (K-TAFS) in Korean samples.

Methods In this study, 628 university students and 93 patients with obsessive-compulsive disorder (OCD) completed the K-TAFS and several other psychological scales. Descriptive analyses, correlations, group comparisons, and exploratory and confirmatory factor analyses were performed.

Results The results of the exploratory and confirmatory factor analyses indicated a two-factor structure with TAF-Morality and TAFLikelihood that best fits the data in the university sample. The reliability analyses showed that TAFS and its factors had excellent internal consistencies. Regarding the concurrent validity, positive correlations were observed between TAF-Likelihood and cognitive fusion, while the TAFS scores did not show any consistent correlations with other symptoms such as depression and anxiety. Compared to the university students, the OCD patients showed higher TAFS scores and their obsessive-compulsive symptoms were significantly associated with both TAF-Morality and TAF-Likelihood.
\end{abstract}

Conclusion Overall, the findings of this study support the reliability and validity of the K-TAFS.

Psychiatry Investig 2021;18(4):348-356

Key Words Thought-action fusion, Thought-Action Fusion Scale, Obsessive-compulsive disorder, Cognitive bias, Psychometric properties.

\section{INTRODUCTION}

Thought-action fusion (TAF) was first introduced by Rach$\operatorname{man}^{1}$ who described fusion as a psychological phenomenon of regarding obsession and a forbidden action as being morally equivalent. Later, the term TAF was expanded to include likelihood TAF in addition to moral TAF. It is defined as "the belief that (one's) specific intrusive thoughts can directly influence the relevant external event and/or the belief that having these intrusive thoughts is morally equivalent to carrying out

Received: October 31, 2020 Revised: December 18, 2020 Accepted: January 21, 2021

$\triangle$ Correspondence: Seung Jae Lee, MD, PhD

Department of Psychiatry, School of Medicine, Kyungpook National University, 680 Gukchaebosang-ro, Jung-gu, Daegu 41944, Korea Tel: +82-53-200-5752, Fax: +82-53-426-5361, E-mail: jayleemd@knu.ac.kr

(a) This is an Open Access article distributed under the terms of the Creative Commons Attribution Non-Commercial License (https://creativecommons.org/licenses/bync/4.0) which permits unrestricted non-commercial use, distribution, and reproduction in any medium, provided the original work is properly cited. a prohibited action."2 This means that the distinction between thinking and behavior becomes ambiguous and an individual tends to establish a wrong causal relationship between their thoughts and external reality through TAF.

The construct of TAF was originally derived from the observation of the obsessive-compulsive (OC) phenomena. ${ }^{3,4} \mathrm{It}$ was suggested that, for some patients, the psychological fusion of thoughts and actions is a vital part of the catastrophic misinterpretation (e.g., "I am responsible for any possible harm."). ${ }^{4}$ Because of the faulty TAF appraisals, individuals with TAF are particularly prone to experience a sense of inflated responsibility. They are likely to think, at least in part, that they have contributed to the occurrence of the negative event and that they should take whatever necessary action to prevent the harm (e.g., neutralization). In other words, TAF is a type of cognitive distortion that acts as an internal source of responsibility. ${ }^{4}$

Shafran et al. ${ }^{4}$ conceptualized TAF as a construct that is particularly significant in obsessive-compulsive disorder (OCD) 
pathology based on preliminary findings that the TAF subscale, which was one of the four factors of the Responsibility Appraisal Questionnaire, was significantly correlated with obsession and guilt even after controlling for depression. ${ }^{3}$ They developed the Thought-Action Fusion Scale (TAFS) ${ }^{4}$ which was divided into two subscales: TAF-Likelihood and TAF-Morality. The former refers to the distorted cognitive appraisal that increases the importance and the feasibility of the event and the latter means that negative thinking is the same as actually committing an action. ${ }^{4}$ TAF-Likelihood leads to compensatory reactions, such as situation avoidance or obsessive rituals, in order to neutralize aversive thoughts or prevent the occurrence of catastrophic consequences, whereas TAF-Morality triggers cognitive avoidance strategies, such as thought suppression, in order to reduce disturbing thoughts and extreme discomfort. Moreover, small to moderate correlations between the TAF scores and OC symptoms were consistently reported $(\mathrm{r}=$ 0.20-0.38). ${ }^{5,6}$ Moreover, experimentally induced TAF was a powerful trigger for intrusive thoughts, guilt, responsibility, and neutralization. ${ }^{7}$

Since the development of the TAFS, this measure has been extensively used to investigate the intermediate processes between the occurrence of intrusive thoughts and compulsive behaviors. As research on TAF was expanded, studies that explored its relevance to symptoms other than OCD have been conducted. One study reported no significant difference in TAFMorality between the OCD group and the generalized anxiety disorder (GAD), panic disorder, social phobia, depression, or non-patient groups, but showed that the OCD group had higher scores in TAF-Likelihood than the other groups. ${ }^{8}$ It was also suggested that TAF may be a useful construct that distinguishes obsessive features from pathological worries. ${ }^{9}$ While these studies demonstrated the diagnostic utility of TAF, other studies showed its transdiagnostic utility such that TAF exists across major mental disorders including major depressive disorder and GAD. ${ }^{10,11}$ This transdiagnostic approach suggests that the TAF bias can be identified as a treatment target and alleviated through psychoeducational interventions, which could reduce general psychological distress or neutralization. ${ }^{12,13}$ This indicates that TAF will not only likely be a diagnostically transcendental factor for major mental disorders, but research on TAF can also contribute to advances in therapeutic techniques.

As such, the TAFS has a useful clinical value in the identification and intervention stages of OCD or other mental disorders. However, few studies in Korea have examined the validity and utility of the TAFS as an instrument for various clinical or nonclinical samples including OCD patients. In fact, without being standardized in a Korean sample, a Korean version of the TAFS ${ }^{14}$ has been used in a handful of studies. Only one preliminary study reported the reliability and factor structure of the Korean version of the TAFS. ${ }^{15}$ Therefore, it would be necessary to validate the Korean version of the TAFS and investigate the sample characteristics and cultural differences in order to broaden the clinical practice of the TAF concept in Korea. The aim of this study is to evaluate the psychometric properties of the Korean version of the TAFS in nonclinical (university medical students) and clinical (OCD patients) samples. In this study, the factor structure, reliability, concurrent validity, and criterion validity of the Korean version of the TAFS were investigated.

\section{METHODS}

\section{Participants}

Undergraduate medical students at the Kyungpook National University School of Medicine were recruited as a nonclinical sample for this study in 2019 to 2020 . Individuals with previous or current history of psychiatric or neurological diagnoses, severe medical illness, a score of 15 or above on the Beck Depression Inventory-II (BDI-II), or any significant missing data were excluded, removing a total of 28 individuals from the sample. The final nonclinical sample consisted of 628 medical students [ 457 men and 171 women; mean age $( \pm S D)=21.6 \pm$ 2.7, ranging from 18 to 32 years].

Nighty-three OCD patients aged between 18 and 40 years were recruited from the outpatient department of psychiatry of Kyungpook National University Hospital as a clinical sample of this study through advertisements posted on local subway stations and an online bulletin board in 2017 to 2020. Psychiatric interviews were performed by two experienced psychiatrists for differential diagnoses in accordance with the DSM-5 criteria. Individuals were excluded if they had any current comorbid psychiatric diagnosis (e.g., major depressive disorder, alcohol use disorder, schizophrenia spectrum and other psychotic disorders, and intellectual disability), neurological disorders, or a history of head injury or medical illness with cognitive sequelae. The final clinical sample consisted of 93 patients. The mean age of the participants was $26.2 \pm 7.3$ years, and they were predominately men $(n=68)$. The data from the clinical sample was used to examine the criterion validity.

All participants provided written informed consent after they were briefed about the research protocol. This study was approved by the Institutional Review Board of Kyungpook National University Hospital (2018-04-029).

\section{Psychological measures}

All measures were administered to both nonclinical and clinical samples except the Obsessive-Compulsive Inventory-Revised and Dimensional Obsessive-Compulsive Scale which were administered only to the OCD patients. 


\section{Thought-Action Fusion Scale (TAFS)}

The TAFS ${ }^{4}$ is a 19-item instrument used to assess a set of cognitive biases related to OCD. The original scale had three subscales: TAFS-Morality [TAFS-M (12 items), e.g., "Thinking of cheating in a personal relationship is almost as immoral to me as actually cheating"], TAFS-Likelihood-for-Others [TAFSLO (4 items), e.g., "If I think of a relative/friend losing their job, this increases the risk that they will lose their job"], and TAFS-Likelihood-for-Self [TAFS-LS (3 items), e.g., "If I think of myself being in a car accident, it increases the risk that I will have a car accident."]. The TAFS-LO and TAFS-LS subscales can be combined into TAFS-Likelihood (TAFS-L). Each item is rated on a scale from 0 (disagree strongly) to 4 (agree strongly) with higher scores indicating a greater TAF. In the present study, a translated Korean version of the TAFS was used. ${ }^{14}$ The TAFS showed good internal consistency in both nonclinical (TAFS-total: $\alpha=0.92$; TAFS-M: $\alpha=0.93$; TAFS-L: $\alpha=0.93$ ) and clinical samples (TAFS-total: $\alpha=0.93$; TAFS-M: $\alpha=0.93$; TAFS-L: $\alpha=0.92$ ).

Past research validated both two-component (i.e., TAFS-M, TAFS-L) and three-component (i.e., TAFS-M, TAFS-LO, TAFSLS) structures in community samples through principal component analysis (PCA)., ${ }^{4,16}$ However, some researchers criticized the limits of PCA (e.g., a data reduction technique) and performed an exploratory factor analysis (EFA)/confirmatory factor analysis (CFA) framework instead. ${ }^{18}$ Based on the results from the maximum likelihood estimation, oblique rotation, and parallel analysis, they proposed a two-factor model with TAFS-M and TAFS-L, which was considered the most acceptable and parsimonious model. Their CFA showed a good fit with the specification of error covariances for items with similar contents. This two-factor model was also validated in a Turkish sample. ${ }^{17}$ Regarding the Korean version of the TAFS, one preliminary study ${ }^{15}$ reported a two-factor solution using an EFA in a sample of 215 college students.

\section{Beck Depression Inventory-II (BDI-II)}

The BDI-II has 21 items that evaluate the cognitive, behavioral, affective, and somatic components of depression, which are scored on a 4-point Likert scale. In this measure, the participants are asked to choose a statement that best describes their state over the past week. The BDI-II has good psychometric properties. ${ }^{19}$ In the present study, the validated Korean version of the Beck Depression Inventory-II was used to assess the occurrence and severity of the depressive symptoms, ${ }^{20}$ and found to have very good internal consistency in our nonclinical $(\alpha=0.75)$ and clinical sample $(\alpha=0.93)$.

\section{Beck Anxiety Inventory (BAI)}

The BAI is a 21-item self-report measure that assesses the severity of anxiety symptoms (Beck et al. ${ }^{21}$ ). It evaluates the degree of discomfort caused by the symptoms described in each question over the past week using a 4-point Likert scale. The Korean version of the Beck Anxiety Inventory (K-BAI) ${ }^{22}$ was used in this study. The internal consistency was 0.81 and 0.95 for our nonclinical and clinical samples, respectively.

\section{Cognitive Fusion Questionnaire (CFQ)}

The $\mathrm{CFQ}^{23}$ is a seven-item self-report measure to assess excessive attachment to the literal content of thoughts. The items evaluate the tendency of thought entanglement and are rated on a scale from 1 ("never true") to 7 ("always true"). Higher scores indicate higher levels of cognitive fusion. The CFQ has demonstrated excellent internal reliability ( $\alpha=0.88$ to 0.93 ) in both clinical and nonclinical samples. ${ }^{23,24}$ In the present sample, the internal consistency was 0.91 for the nonclinical sample and 0.94 for the clinical sample.

\section{Obsessive-Compulsive Inventory-Revised (OCI-R)}

The OCI- $\mathrm{R}^{25}$ is an 18-item questionnaire that assesses the degree to which an individual has felt distressed or bothered by OCD symptoms during the past month. Each item is rated using a 5-point Likert scale from 0 ("not at all") to 4 ("extremely"). Its subscales assess six types of symptoms: 1) washing, 2) checking, 3) obsessing, 4) mental neutralizing, 5) ordering, and 6) hoarding. A score of 21 or greater is a recommended cutoff for the presence of OC symptomatology. The OCI-R showed good internal consistency in the clinical sample (Cronbach's $\alpha=0.91$ ). In this study, a validated Korean version of the OCI-R was used and administered only to the OCD patients. ${ }^{26}$

\section{Dimensional Obsessive-Compulsive Scale (DOCS)}

The $\mathrm{DOCS}^{27}$ is a 20 -item self-report measure that assesses the severity of the four most consistently replicated OC symptom dimensions: 1) contamination, 2) responsibility for harm and mistakes, 3) unacceptable thoughts, and 4) symmetry and ordering. Each item is rated on a 5-point Likert scale, yielding individual subscale scores ranging from 0 to 20 and a total score ranging from 0 to 80 . The DOCS subscales have excellent reliability in clinical samples, and the measure corresponds well with other measures of OC symptoms. The Korean version of the DOCS subscales showed good internal consistency (Cronbach's $\alpha=0.91-0.95$ ). In this study, a validated Korean version of the DOCS was used and administered only to the OCD patients. ${ }^{28}$

\section{Statistical analysis}

The Kolmogorov-Smirnov test was used as the goodness of fit index to assess the normality of the distribution of the TAFS. The test results indicated that the total and subscale 
scores of the TAFS were not normally distributed. Thus, nonparametric statistics were used whenever appropriate. Levene's test was used to examine the equality of variances. When the assumption of homogeneity of variance was violated, the Welch's test results were reported. Chi-square tests were used for model comparisons, and independent samples t-tests and the analysis of covariance (ANCOVA) were used for group comparisons. The internal consistency of the TAFS and its subscales was estimated using Cronbach's alpha. To assess the concurrent validity of the scale, the Spearman's correlations between TAFS and CFQ were analyzed. To assess its discriminant validity, the Spearman's correlations between TAFS, BDI-II, and BAI were analyzed. Additionally, the Spearman's correlations between TAFS, OCI-R, and DOCS were analyzed in OCD patients in order to examine the criterion validity. All statistical analyses were performed using the IBM SPSS Statistics for Windows, version 23 (IBM Corp., Armonk, NY, USA) and statistical significance was set at $\mathrm{p}<0.05$.

Confirmatory factor analyses (CFA) were performed using the AMOS 20 software in the IBM SPSS. ${ }^{29}$ The maximum likelihood (ML) estimation approach was used to estimate the parameters. To evaluate the goodness of fit of the CFA models, multiple indices were selected, including the chi-square statistic, comparative fit index (CFI), ${ }^{30}$ goodness of fit index (GFI), ${ }^{31}$ root mean square residual (RMSR), ${ }^{31}$ and root mean square error of approximation (RMSEA), ${ }^{32}$ because each of these indices provides somewhat different information. As a general rule, $\mathrm{CFI}>0.90, \mathrm{GFI}>0.90, \mathrm{RMSR}<0.10$, and $\mathrm{RMSEA}<0.10$ are considered adequate fit. ${ }^{33}$

\section{RESULTS}

\section{Descriptive statistics}

The mean $( \pm S D)$ of the TAFS-total, TAFS-M, and TAFS-L subscale scores were $24.9 \pm 12.9,20.8 \pm 10.6$, and $4.0 \pm 5.0$, respectively, in the nonclinical sample (Table 1). No significant gender difference was found in TAFS-total and TAFS-L ( $\mathrm{t}=-1.85$, $\mathrm{df}=352.8, \mathrm{p}=0.066 ; \mathrm{t}=0.73, \mathrm{df}=626, \mathrm{p}=0.464$, respectively), whereas a significant gender difference was observed in the TAFS-M scores. Specifically, women tended to have a higher level of TAFS-M than men (male $=20.2 \pm 11.0$, female $=22.5 \pm 9.5 ; \mathrm{t}=-2.60$, $\mathrm{df}=350.3, \mathrm{p}=0.010$, Cohen's $\mathrm{d}=0.23$ ). Age was negatively associated with TAFS-total and TAFS-M, indicating that younger participants were more likely to have TAF in general or TAFMorality (Spearman's $r=-0.16, p<0.001$, for TAFS-total; $r=-0.17$, $\mathrm{p}<0.001$, for TAFS-M). In the clinical sample, the mean $( \pm S D)$ of the TAFS-total, TAFS-M, and TAFS-L subscale scores were $30.4 \pm 16.6,19.9 \pm 12.0$, and $10.4 \pm 7.5$, respectively (Table 1 ). A significant gender difference was found in TAFS-total, indicating that women tended to have a higher level of TAFS-total than men (male $=28.2 \pm 15.9$, female $=36.1 \pm 17.4 ; \mathrm{t}=-2.06, \mathrm{df}=91$, $\mathrm{p}=0.042$, Cohen's $d=0.483$ ). Gender differences were marginally significant in TAFS-M and TAFS-L in the same direction $(t=-1.76, d f=91, p=0.081$, Cohen's $d=0.41 ; t=-1.75, d f=91, p=$

Table 1. Demographic and psychological data for medical students and OCD patients

\begin{tabular}{|c|c|c|c|c|c|c|}
\hline & \multicolumn{2}{|c|}{ Students $(\mathrm{N}=628)$} & \multicolumn{2}{|c|}{$\mathrm{OCD}(\mathrm{N}=93)$} & \multicolumn{2}{|c|}{ Statistics } \\
\hline & Mean & $\mathrm{SD}$ & Mean & SD & $\chi^{2} / t$ & $\mathrm{p}$ \\
\hline Male/female (number) & \multicolumn{2}{|c|}{$457 / 171$} & \multicolumn{2}{|c|}{$68 / 25$} & 0.01 & 0.944 \\
\hline Age (year) & 21.6 & 2.7 & 26.2 & 7.3 & -11.3 & $<0.001$ \\
\hline \multicolumn{7}{|l|}{ Thought-Action Fusion Scale } \\
\hline TAFS-Morality & 20.8 & 10.6 & 19.9 & 11.9 & 0.8 & 0.443 \\
\hline TAFS-Likelihood & 4.0 & 5.0 & 10.4 & 7.5 & -8.0 & $<0.001$ \\
\hline TAFS-Total & 24.9 & 12.9 & 30.3 & 16.6 & -3.7 & $<0.001$ \\
\hline Cognitive Fusion Questionnaire & 16.1 & 8.1 & 37.6 & 10.4 & -21.4 & $<0.001$ \\
\hline Beck Depression Inventory II & 3.4 & 3.4 & 20.0 & 11.8 & -16.5 & $<0.001$ \\
\hline Beck Anxiety Inventory & 1.1 & 2.3 & 20.8 & 14.5 & -19.6 & $<0.001$ \\
\hline Obsessive-Compulsive Inventory-Revised & \multicolumn{2}{|c|}{-} & 34.3 & 14.2 & \multicolumn{2}{|c|}{-} \\
\hline \multicolumn{7}{|l|}{ Dimensional Obsessive-Compulsive Scale } \\
\hline DOCS-contamination & \multicolumn{2}{|c|}{-} & 6.3 & 4.8 & \multicolumn{2}{|c|}{-} \\
\hline DOCS-responsibility for harm & \multicolumn{2}{|c|}{-} & 8.9 & 5.6 & \multicolumn{2}{|c|}{-} \\
\hline DOCS-unacceptable thoughts & \multicolumn{2}{|c|}{-} & 9.7 & 5.4 & \multicolumn{2}{|c|}{-} \\
\hline DOCS-symmetry/ordering & \multicolumn{2}{|c|}{-} & 5.9 & 5.6 & \multicolumn{2}{|c|}{-} \\
\hline DOCS-total & \multicolumn{2}{|c|}{-} & 30.7 & 13.7 & \multicolumn{2}{|c|}{-} \\
\hline
\end{tabular}

OCD: obsessive-compulsive disorder, TAFS: Thought-Action Fusion Scale, DOCS: Dimensional Obsessive-Compulsive Scale 
0.084, Cohen's $\mathrm{d}=0.41$ ). Compared with the nonclinical sample, age was significantly correlated with TAFS-total ( $r=-0.22$, $\mathrm{p}=0.033$ ) and marginally correlated with TAFS-M and TAFS-L in the clinical sample (Spearman's $r=-0.20, p=0.053$, for TAFS$\mathrm{M} ; \mathrm{r}=-0.19, \mathrm{p}=0.069$, for TAFS-L), all of which indicate that younger participants were more likely to have TAF.

\section{Factor structure}

Both an EFA and a CFA were performed to examine the factor structure of the TAFS. The nonclinical sample was divided into two subsamples by using a random group generator with participant identifiers (1 to 628). Following the guideline from Anderson and Gerbing, ${ }^{34}$ Subsample 1 was used to conduct an EFA $[n=333 ; 234$ males, 99 females; average $( \pm S D)$ age $=21.70 \pm$ 2.76)] and Subsample 2 was used to cross-validate those factors $(\mathrm{CFA})[\mathrm{n}=295 ; 223$ males, 72 females; average $( \pm \mathrm{SD})$ age $=$ $21.44 \pm 2.64)$ ]. There was no significant difference between two subsamples in terms of age, TAFS-M, TAFS-L, TAFS-total, CFQ, BDI-II, and BAI $[\mathrm{F}(1,626)=1.366, \mathrm{~F}(1,626)=0.264, \mathrm{~F}(1$, $626)=0.523, \mathrm{~F}(1,626)=0.493, \mathrm{~F}(1,626)=2.356, \mathrm{~F}(1,626)=1.732$, $\mathrm{F}(1,626)=0109$, all n.s., respectively].

An EFA was performed on Subsample 1 using ML estimation and oblique rotation (Direct Oblimin with delta $=0$ ). The inspection of the scree plot revealed a two-factor solution with eigenvalues of 7.43 and 4.17. The explained variances for these two factors were $33.44 \%$ and $23.25 \%$, respectively. These two factors perfectly match TAF-L and TAF-M. The correlation between two factors was 0.267 . A three-factor solution was not preferred as the third factor had a low initial eigenvalue $(=1.06)$, a small explained variance $(=4.58)$, and a high correction with TAFS-M (=-0.68). The three items loaded on the third factor were items 2,10 , and 18, which have the content of sinful or obscene thoughts or gestures. Thus, TAFS-LS and TAFS-LO were not separated as unique factors but combined as TAF-L. This result was consistent with the original study (Revised TAF Scale items) and the previous study results that performed an EFA. ${ }^{4,15,16}$

A CFA was conducted on Subsample 2 to cross-validate the two-factor model. This confirmatory model was close to an acceptable fit with the data $\left[\chi^{2}(151)=553.959, \mathrm{p}<0.001\right.$; CFI $=$ $0.903, \mathrm{GFI}=0.823 ; \mathrm{RMSR}=0.070 ; \mathrm{RMSEA}=0.095]$. To enhance a goodness of fit, the CFA mode was respecified with three correlated residuals based on the EFA (items 2, 10, and 18). This revised CFA showed an improved fit with $\chi^{2}(148)=472.201$, $\mathrm{p}<0.001 ; \mathrm{CFI}=0.922$, GFI=0.845; RMSR $=0.065 ; \mathrm{RMSEA}=0.086$. All factor loadings exceeded 0.60 (range $=0.61-0.84$ for TAFS$\mathrm{M}, 0.66-0.92$ for TAF-L), and the factor loadings were high in strength (average $r=0.77$ ) (Table 2). The correlation between two factors in this revised model was 0.26 .

\section{Reliability}

Internal consistency was computed using Cronbach's $\alpha$. TAFS showed a high internal consistency in both samples. In the nonclinical sample, the Cronbach's alpha coefficients were 0.92 for TAFS-total, 0.93 for TAFS-M, and 0.93 for TAFS-L. Itemtotal correlations varied from 0.47 (item no. 4 for TAFS-L) to 0.70 (item no. 8 for TAFS-M). For OCD patients, the Cronbach's alpha coefficients were 0.93 for TAF-total, 0.93 for TAFS$\mathrm{M}$, and 0.92 for TAFS-L. Item-total correlations varied from 0.58 (item no. 3 for TAFS-L) to 0.77 (item no. 12 for TAFS-M).

\section{Concurrent validity}

In order to evaluate the convergent and discriminant validity of the TAF factors, the Spearman's correlations between TAFS and other measures were examined in both nonclinical and clinical samples (Table 3).

Regarding the convergent validity of the TAFS factors, TAFSL was positively correlated with the CFQ score in both nonclinical and clinical samples $(r=0.30 \mathrm{p}<0.001$ and $\mathrm{r}=0.26, \mathrm{p}=$ 0.053 , respectively), whereas TAFS-M was not significantly correlated with the CFQ scores in both samples. With regard to the discriminant validity of the TAFS factors, TAFS-L and TAFS-M did not show any consistent correlation patterns with depression and anxiety. Specifically, TAFS-L was significantly correlated with both BDI-II and BAI in the nonclinical sample $(r=0.19 \mathrm{p}<0.001$ and $\mathrm{r}=0.12 \mathrm{p}=0.004$, respectively), but the associations were relatively weak. The pattern was different in the OCD sample such that TAFS-L was significantly correlated with BDI-II ( $\mathrm{r}=0.28, \mathrm{p}=0.007)$, but not with BAI.

\section{Criterion validity}

A one-way analysis of variance was conducted to compare the TAFS scores of the OCD patients with those of the undergraduate students. The analysis revealed that the OCD patients had higher levels of TAFS-total and TAFS-L scores than the university students. However, no group difference was observed in TAFS-M (Table 1). The same results were sustained even after controlling for age in the analysis of covariates (ANCOVA) $\left[\mathrm{F}(1,718)=24.5, \mathrm{p}<0.001, \omega^{2}=0.031\right.$, for TAFS-total; $\mathrm{F}(1,718)=$ $0.63, \mathrm{p}=0.428$, for TAFS-M; $\mathrm{F}(1,718)=115.34, \mathrm{p}<0.001, \omega^{2}=$ 0.136 , for TAFS-L].

Correlational analyses were performed in the OCD sample to examine the association between TAFS and OCD symptoms. In the OCD patients, both TAFS-M and TAFS-L were significantly correlated with OCI total scores $(r=0.23 \mathrm{p}=0.024$; $\mathrm{r}=0.35, \mathrm{p}<0.001$, respectively) and DOCS total scores $(\mathrm{r}=0.25$ $\mathrm{p}=0.018$ and $\mathrm{r}=0.24 \mathrm{p}=0.019$, respectively). These results remained significant even after controlling for age (partial $r=$ $0.27, \mathrm{p}=0.010$ for TAFS-M, partial $\mathrm{r}=0.37, \mathrm{p}<0.001$ for TAFS-L with OCI total; partial $\mathrm{r}=0.26, \mathrm{p}=0.014$ for TAFS-M, partial 


\begin{tabular}{|c|c|c|c|}
\hline & \multirow[b]{2}{*}{ TAFS Item } & \multicolumn{2}{|c|}{ Factor } \\
\hline & & $\begin{array}{c}\text { Moral } \\
\text { (TAFS-M) }\end{array}$ & $\begin{array}{l}\text { Likelihood } \\
\text { (TAFS-L) }\end{array}$ \\
\hline Item 1 & 친구에게 아주 심한 말을 하는 생각은 실제로 그것을 말한 것만큼이나 용납할 수 없다. & 0.72 & \\
\hline Item 2 & 신성모독적인 생각을 하면 신성모독적인 행동을 한 것만큼이나 죄스럽다. & 0.65 & \\
\hline Item 5 & 다른 사람을 욕하는 생각은 실제로 욕하는 것만큼이나 용납할 수 없다. & 0.71 & \\
\hline Item 6 & 다른 사람에 대해 추잡한 생각을 하는 것은 추잡한 행동을 하는 것만큼이나 나쁘다. & 0.82 & \\
\hline Item 8 & 폭력적인 생각을 하면 폭력행동을 하는 것만큼이나 용납할 수 없다. & 0.76 & \\
\hline Item 10 & 교회에서 음란한 말이나 제스처를 하는 생각을 하는 것은 그것을 실제로 하는 것만큼이나 죄스럽다. & 0.73 & \\
\hline Item 11 & 다른 사람에게 해를 끼치고 싶어하는 것은 실제로 해를 끼치는 것만큼이나 나쁘다. & 0.84 & \\
\hline Item 12 & 다른 사람에게 음란한 제스처를 하는 생각을 하는 것은 이를 실제로 하는 것만큼이나 나쁘다. & 0.84 & \\
\hline Item 13 & 친구에 대해 좋지 않게 생각하는 것은 좋지 않게 행동하는 것만큼이나 배신이다. & 0.73 & \\
\hline Item 15 & 시샘하는 생각을 하는 것은 시샘하는 말을 하는 것과 거의 같다. & 0.61 & \\
\hline Item 17 & 인간관계에서 속이는 생각을 하는 것은 실제로 속이는 것만큼이나 부도덕하다. & 0.71 & \\
\hline Item 18 & 교회에서 음란한 생각을 하는 것을 나로서는 용납할 수 없다. & 0.66 & \\
\hline Item 3 & 친척(혹은 친구)이 직장을 잃는 생각을 하면 실제로 이들이 직장을 잃을 것 같다. & & 0.81 \\
\hline Item 9 & 친척(혹은 친구)이 차 사고를 당하는 생각을 하면 실제로 이들이 차사고를 당할 것 같다. & & 0.86 \\
\hline Item 14 & 친척(혹은 친구)이 떨어져서 다치는 생각을 하면 실제로 이들이 떨어져서 다칠 것 같다. & & 0.89 \\
\hline Item 19 & 친척(혹은 친구)이 병드는 생각을 하면 실제로 이들이 병에 걸릴 것 같다. & & 0.92 \\
\hline Item 4 & 내가 떨어져서 다치는 생각을 하면 실제로 내가 떨어져서 다칠 것 같다. & & 0.82 \\
\hline Item 7 & 나 자신이 사고를 당하는 생각을 하면 실제로 내가 차사고를 당할 것 같다. & & 0.86 \\
\hline Item 16 & 내가 병드는 생각을 하면 실제로 내가 병들 것 같다. & & 0.66 \\
\hline
\end{tabular}

TAFS-M, -L: Thought-Action Fusion Scale-Morality, -Likelihood

Table 3. Spearman's correlations between the Thought-Action Fusion Scale and other measures in medical students $(\mathrm{N}=628)$ and OCD patients $(\mathrm{N}=93)$

\begin{tabular}{lcccccc}
\hline & 1 & 2 & 3 & 4 & 5 & 6 \\
\hline 1. TAFS-M & & $0.41^{\ddagger}$ & $0.91^{\ddagger}$ & 0.17 & 0.19 & $0.36^{\dagger}$ \\
2. TAFS-L & $0.25^{\ddagger}$ & & 0.73 & 0.26 & $0.28^{\dagger}$ & 0.19 \\
3. TAFS-Total & $0.93^{\ddagger}$ & $0.56^{\ddagger}$ & & 0.23 & $0.24^{*}$ & $0.37^{\dagger}$ \\
4. CFQ & -0.06 & $0.30^{\ddagger}$ & 0.05 & & $0.52^{\ddagger}$ & $0.51^{\ddagger}$ \\
5. BDI-II & -0.06 & $0.19^{\ddagger}$ & 0.01 & $0.45^{\ddagger}$ & & $0.76^{\ddagger}$ \\
6. BAI & 0.00 & $0.12^{\dagger}$ & 0.03 & $0.39^{\ddagger}$ & $0.51^{\ddagger}$ & \\
\hline
\end{tabular}

Bottom-left off-diagonal correlations for medical students, topright off-diagonal correlations for OCD patients. ${ }^{*} \mathrm{p}<0.05,{ }^{\dagger} \mathrm{p}<0.01$, ${ }^{\ddagger} \mathrm{p}<0.001$. OCD: obsessive-compulsive disorder, TAFS-M, -L, -Total: Thought-Action Fusion-Morality, -Likelihood, -Total, CFA: Cognitive Fusion Questionnaire, BDI-II: Beck Depression Inventory, second edition, BAI: Beck Anxiety Inventory

$\mathrm{r}=0.25, \mathrm{p}=0.015$ for TAFS-L with DOCS total). Among the DOCS subscales, the two symptom dimensions of responsibility for harm and mistakes and unacceptable thoughts were consistently associated with both TAFS-M and TAFS-L (Table 4). These results remained significant even after controlling for age (partial $r=0.30, p=0.004$, for TAFS-M, partial $r=0.29$, $\mathrm{p}=0.005$, for TAFS-L with DOCS-responsibility; partial $\mathrm{r}=0.26$, $\mathrm{p}=0.013$, for TAFS-M, partial $\mathrm{r}=0.21, \mathrm{p}=0.048$, for TAFS-L with DOCS-unacceptable thoughts).

\section{DISCUSSION}

The present study examined the psychometric properties of the Korean version of the TAFS and the results revealed its cross-cultural validity in Korean samples.

The findings of this study indicate that the results from our nonclinical TAFS data were consistent with the previous studies that reported 19 to 24 as the average of the TAFS-total scores. ${ }^{4,8,9,35,36}$ TAFS-L showed positively skewed distributions in both nonclinical and clinical samples, although the TAFS$\mathrm{M}$ subscale was not much skewed in both samples. These differential findings may stem from the fact that the TAFS was originally developed to measure a cognitive "bias" that is not typical of routine cognitive processes and that the morality bias can be more common and less pathological than the likelihood bias. ${ }^{4}$ Regarding gender differences, the female participants had a higher level of TAFS-M than male participants in this study, which was significant in the nonclinical sample and marginally significant with a high effect size in the clinical sample. This difference may be partially due to the general notion 
Table 4. Spearman's correlations between Thought-Action Fusion Scale and obsessive-compulsive symptom dimension in OCD patients $(\mathrm{N}=93)$

\begin{tabular}{lcccccc}
\hline & OCI-R & DOCS-total & DOCS-C & DOCS-R & DOCS-U & DOCS-S \\
\hline TAFS-M & $0.23^{*}$ & $0.25^{*}$ & 0.01 & $0.28^{*}$ & $0.24^{*}$ & 0.12 \\
TAFS-L & $0.35^{\ddagger}$ & $0.24^{*}$ & 0.09 & $0.29^{\dagger}$ & $0.21^{*}$ & 0.06 \\
TAF-Total & $0.35^{\ddagger}$ & $0.29^{\dagger}$ & 0.05 & $0.35^{\ddagger}$ & $0.26^{*}$ & 0.11 \\
\hline
\end{tabular}

${ }^{*} \mathrm{p}<0.05,{ }^{\dagger} \mathrm{p}<0.01,{ }^{\mathrm{t}} \mathrm{p}<0.001$. OCD: obsessive-compulsive disorder, TAFS-M, -L, -Total: Thought-Action Fusion-Morality, -Likelihood, -Total, OCI: Obsessive-Compulsive Inventory-Revised, DOCS: Dimensional Obsessive-Compulsive Scale, DOCS-C, -R, -U, -S: DOCS-Contamination, -Responsibility, -Unacceptable thoughts, -Symmetry

that women have higher moral standards than men, at least in competitive contexts. ${ }^{37-39}$ A majority of participants in most previous studies were female (e.g., $64 \%$ to $84 \%$ of the samples were female $)^{4,5,17}$ and these studies did not provide the TAFS scores according to gender. Only one study reported no gender differences in TAFS-total and its subscales in adolescents. ${ }^{40}$ Therefore, future studies should explore the role of gender in the cognitive processes of TAF.

Factor analyses indicated that a two-factor structure of the Korean version of the TAFS provided an acceptable fit to the data in the nonclinical sample. Even though the original scale had three subscales (i.e., TAFS-M, TAFS-LO, TAFS-LS) and some studies supported both two-component and three-component structures based on PCA, the present study supported a two-factor solution with TAFS-M and TAFS-L as a parsimonious and acceptable model based on the EFA and CFA. The two-factor structure is consistent with the past research based on factor analyses and was supported in clinical ${ }^{18}$ and nonclinical samples. ${ }^{17,36}$ Items loaded on each factor perfectly matched with TAFS-M and TAFS-L in the original scale. ${ }^{4}$ The correlation between two factors was moderately high in our sample. More recently, a bifactor model was proposed with a global TAFS factor (subsuming both TAFS-M and TAFS-L) and a TAFS-L domain-specific factor. ${ }^{41}$ Although an additional analysis with our data showed an acceptable fit with the bifactor model, this model was not supported by our EFA and has not gained a theoretical rationale or empirical support yet. Further research on the bifactor model may be necessary in order to examine the utility of this model.

The results of the present study indicate that TAFS is a highly reliable construct in both nonclinical and clinical samples. Reliability analyses showed that the Korean version of the TAFS and its factors had excellent internal consistencies, in comparison with the original ( 0.85 to 0.96 of $\alpha s)^{4}$ and extended studies ( 0.75 to 0.89 of $\alpha s)^{36}$ and the Turkish version ( 0.85 to 0.92 of $\left.\alpha s\right){ }^{17}$

With regard to convergent validity, positive correlations were found between TAFS-L and CFQ, whereas no significant correlation was observed between TAFS-M and CFQ. Cognitive fusion, measured by the CFQ, is a tendency to take internal thoughts and feelings literally and have behavior overly regulated by cognition (e.g., "I tend to get very entangled in my thoughts"), which has conceptual overlaps with TAF. ${ }^{6}$ According to our findings, these conceptual overlaps may be well shown in the association between TAFS-L and CFQ.

In terms of discriminant validity, TAFS did not show any consistent pattern in this study. No significant correlations were observed between TAFS-M and depression or anxiety, whereas TAFS-L showed significant but weak correlations with depression and anxiety in the nonclinical sample. Consistent with our findings, previous studies indicated that TAFS showed no or weak correlations with anxiety or depression ${ }^{4,36,42}$ and that TAFS-L, if any, was found to be more convincingly associated with these symptoms in student or community samples than TAFS-M. ${ }^{4,36,40}$ The OCD patients, on the other hand, demonstrated increased correlations between TAFS-M and anxiety and between TAFS-L and depression in this study. Previous studies suggested that patients with OCD tend to represent moderate correlations between TAFS and depression ${ }^{4,8}$ or anxiety. ${ }^{8}$ These strengthened relationships may result from the mediating effect of negative affect (e.g., depression and anxiety) ${ }^{8,43}$ Regarding differential relationships according to TAFS subcomponents, TAFS-L appears to be related to obsessive symptoms, whereas TAFS-M seems to be related to depression in student or community samples. ${ }^{44}$ In contrast, the non-significant association between TAF-M and depression may be due to the strict exclusion criteria in both nonclinical and clinical samples (i.e., BDI-II score below 15 in the nonclinical sample and no current comorbid psychiatric diagnosis in the clinical sample).

Lastly, the criterion validity of the TAFS was examined by assessing the relationships between the TAFS scores and OC symptoms in the OCD patients. First, the OCD patients showed higher TAFS-total and TAF-L scores than university students, whereas no group difference in TAFS-M was observed. The lack of a group difference in TAFS-M has been established since the TAFS was initially introduced. ${ }^{4,8,36}$ These studies explained that TAF-Morality may be more general and less pathological and may be associated with non-specific depressive symptoms rather than specific OC symptoms. Second, all TAFS scores were significantly correlated with $\mathrm{OC}$ symptoms that were measured by OCI and DOCS. This shows the conceptual connection between TAF and OC symptoms. Previous studies as- 
serted that TAFS-M is not specific to OC symptoms ${ }^{43}$ and that TAFS-L is more likely to be associated with OC symptoms than TAFS-M. ${ }^{43,44}$ Our results based on the OCD sample are not consistent with this perspective but are consistent with one recent study. ${ }^{45}$ As the present study did not assess the OC symptoms in the nonclinical sample, future studies should confirm our results in a nonclinical sample. Third, in terms of the specificity of the OC symptoms, the total and subscale scores of the TAFS were correlated with only two symptom dimensions in DOCS, which were responsibility for harm and mistakes and unacceptable thoughts. These results are consistent with previous studies that examined the associations between CFQ and OC symptoms. ${ }^{45-47}$ Those studies consistently reported that cognitive fusion was a unique predictor of two DOCS dimensions (responsibility for harm and mistakes and unacceptable obsessional thoughts) even after controlling for obsessive belief and depression. Fourth, the pattern of correlations between the TAFS scores and OC symptoms remained the same even after controlling for age. Thus, regardless of age, the TAF and OC symptoms showed significant associations.

Some limitations of the current study should be acknowledged. First, considering that our subjects were medical students, caution is needed in generalizing our findings. Further research with more representative samples including various age groups is needed. Another limitation is that the sample size of OCD patients in this study is not enough to confirm factor structures. Further studies with greater statistical power may be able to more affirmatively explore them.

In conclusion, the TAFS is considered a reliable and valid instrument that can be used in a Korean sample. Future studies are needed to further investigate the degrees of commonality and specificity of TAF across major psychiatric disorders and to confirm the efficacy of this measure in intervention programs such as cognitive defusion in Acceptance and Commitment Therapy ${ }^{48}$ and biological studies such as neuroimaging for examining the underlying mechanism of $\mathrm{TAF}^{49,50}$

\section{Acknowledgments}

This work was supported by the National Research Foundation of Korea (NRF) grant funded by the Korean government (MSIP) (NRF-2018R1A2 B6007374).

\section{Conflicts of Interest}

The authors have no potential conflicts of interest to disclose.

\section{Author Contributions}

Conceptualization: Seung Jae Lee. Data curation: Seung Jae Lee. Formal analysis: all authors. Writing—original draft: Seung Jae Lee. Writing—review \& editing: Soonhee Lee.

\section{ORCID iDs}

$\begin{array}{ll}\text { Seung Jae Lee } & \text { https://orcid.org/0000-0003-3648-9824 } \\ \text { Soonhee Lee } & \text { https://orcid.org/0000-0003-3786-0808 }\end{array}$

\section{REFERENCES}

1. Rachman S. Obsessions, responsibility and guilt. Behav Res Ther 1993; 31:149-154.

2. Rachman S, Shafran R. Cognitive distortions: thought-action fusion. Clin Psychol Psychother 1999;6:80-85.

3. Rachman S, Thordarson DS, Shafran R, Woody SR. Perceived responsibility: structure and significance. Behav Res Ther 1995;33:779-784.

4. Shafran R, Thordarson DS, Rachman S. Thought-action fusion in obsessive compulsive disorder. J Anxiety Disord 1996;10:379-391.

5. Amir N, Freshman M, Ramsey B, Neary E, Brigidi B. Thought-action fusion in individuals with OCD symptoms. Behav Res Ther 2001;39: 765-776.

6. Lee SW, Lee KW, Choi M, Lee SJ. Conceptual understanding of thoughtaction fusion and cognitive fusion: focus on obsessive-compulsive symptoms. Anxiety Mood 2019;15:1-12.

7. Rassin E, Merckelbach H, Muris P, Spaan V. Thought-action fusion as a causal factor in the development of intrusions. Behav Res Ther 1999; 37:231-237.

8. Abramowitz JS, Whiteside S, Lynam D, Kalsy S. Is thought-action fusion specific to obsessive-compulsive disorder?: a mediating role of negative affect. Behav Res Ther 2003;41:1069-1079.

9. Coles ME, Mennin DS, Heimberg RG. Distinguishing obsessive features and worries: the role of thought-action fusion. Behav Res Ther 2001;39:947-959.

10. Ghamari Kivi H, Mohammadipour Rik N, Sadeghi Movahhed F. Explanation of obsessive-compulsive disorder and major depressive disorder on the basis of thought-action fusion. Iran J Psychiatry Behav Sci 2013;7:44-50.

11. Thompson-Hollands J, Farchione TJ, Barlow DH. Thought-action fusion across anxiety disorder diagnoses: specificity and treatment effects. J Nerv Ment Dis 2013;201:407-413.

12. Marino-Carper T, Negy C, Burns G, Lunt RA. The effects of psychoeducation on thought-action fusion, thought suppression, and responsibility. J Behav Ther Exp Psychiatry 2010;41:289-296.

13. Zucker BG, Craske MG, Barrios V, Holguin M. Thought action fusion: can it be corrected? Behav Res Ther 2002;40:653-664.

14. Lee S. The Relationships of OC Symptoms with Moral and Causal Responsibility and with Omission. Seoul: Department of Psychology. Seoul National University; 2000.

15. Lee S, Shin M. Is thought-action fusion a cognitive error specific to obsessive-compulsive disorder? Poster presented at the winter meeting of the Korean Clinical Psychological Association; 2004.

16. Pourfaraj M, Mohammadi N, Taghavi M. Psychometric properties of revised Thought-Action Fusion questionnaire (TAF-R) in an Iranian population. J Behav Ther Exp Psychiatry 2008;39:600-609.

17. Yorulmaz O, Yilmaz AE, Gencoz T. Psychometric properties of the Thought-Action Fusion Scale in a Turkish sample. Behav Res Ther 2004;42:1203-1214.

18. Meyer JF, Brown TA. Psychometric evaluation of the thought-action fusion scale in a large clinical sample. Assessment 2013;20:764-775.

19. Beck AT, Steer RA, Brown GK. Beck Depression Inventory-Second Edition Manual. San Antonio: The Psychological Corporation; 1996.

20. Yu BK, Lee HK, Lee KS. Validation and factor structure of Korean version of the Beck Depression Inventory Second Edition (BDI-II): in a university student sample. Korean J Biol Psychiatry 2011;18:126-133.

21. Beck AT, Epstein N, Brown G, Steer RA. An inventory for measuring clinical anxiety: psychometric properties. J Consult Clin Psychol 1988; 56:893-897.

22. Yook SP, Kim ZS. A clinical study on the Korean version of Beck Anxiety Inventory: comparative study of patient and non-patient. Korean J Clin Psychol 1997;16:185-197.

23. Gillanders DT, Bolderston H, Bond FW, Dempster M, Flaxman PE, Campbell L, et al. The development and initial validation of the cognitive fusion questionnaire. Behav Ther 2014;45:83-101. 
24. McCracken LM, DaSilva P, Skillicorn B, Doherty R. The cognitive fusion questionnaire: a preliminary study of psychometric properties and prediction of functioning in chronic pain. Clin J Pain 2014;30:894-901.

25. Foa EB, Huppert JD, Leiberg S, Langner R, Kichic R, Hajcak G, et al. The Obsessive-Compulsive Inventory: development and validation of a short version. Psychol Assess 2002;14:485-496.

26. Woo CW, Kwon SM, Lim YJ, Shin MS. The Obsessive-Compulsive Inventory-Revised (OCI-R): psychometric properties of the Korean version and the order, gender, and cultural effects. J Behav Ther Exp Psychiatry 2010;41:220-227.

27. Abramowitz JS, Deacon BJ, Olatunji BO, Wheaton MG, Berman NC, Losardo D, et al. Assessment of obsessive-compulsive symptom dimensions: development and evaluation of the Dimensional Obsessive-Compulsive Scale. Psychol Assess 2010;22:180-198.

28. Kim HW, Kang JI, Kim SJ, Jhung K, Kim EJ, Kim SJ. A validation study of the Korean-version of the dimensional obsessive-compulsive scale. J Korean Neuropsychiatr Assoc 2013;52:130-142.

29. Arbuckle J. IBM SPSS Amos 20 User's Guide. Mount Pleasant: Amos Development Corporation; 2011.

30. Bentler PM. Comparative fit indexes in structural models. Psychol Bull 1990;107:238-246.

31. Jöreskog KG, Sörbom D. LISREL 7 User's Reference Guide. Chicago: SPSS Publications; 1989.

32. Steiger JH. Structural model evaluation and modification: an interval estimation approach. Multivariate Behav Res 1990;25:173-180.

33. Klein RB. Principles and Practice of Structural Equation Modeling. New York: Guilford; 2005.

34. Anderson JC, Gerbing DW. Structural Equation Modeling in practice: a review and recommended two-step approach. Psychol Bull 1988;103: 411-423.

35. Rassin E, Diepstraten P, Merckelbach H, Muris P. Thought-action fusion and thought suppression in obsessive-compulsive disorder. Behav Res Ther 2001;39:757-764

36. Rassin E, Merckelbach H, Muris P, Schmidt H. The thought-action fusion scale: further evidence for its reliability and validity. Behav Res Ther 2001;39:537-544.

37. Kennedy JA, Kray LJ, Ku G. A social-cognitive approach to understanding gender differences in negotiator ethics: the role of moral identity. Organ Behav Hum Decis Processes 2017;138:28-44.

38. Franke GR, Crown DF, Spake DF. Gender differences in ethical per- ceptions of business practices: a social role theory perspective. J Appl Psychol 1997;82:920-934.

39. Robinson RJ, Lewicki RJ, Donahu EM. Extending and testing a five factor model of ethical and unethical bargaining tactics: introducing the SINS scale. J Organ Behav 2000;21:649-664.

40. Muris P, Meesters C, Rassin E, Merckelbach H, Campbell J. Thoughtaction fusion and anxiety disorders symptoms in normal adolescents. Behav Res Ther 2001;39:843-852.

41. Meyer ML, Masten CL, Ma Y, Wang C, Shi Z, Eisenberger NI, et al. Empathy for the social suffering of friends and strangers recruits distinct patterns of brain activation. Soc Cogn Affect Neurosci 2013;8: 446-454.

42. Bailey Be, Wu KD, Valentiner DP, McGrath PB. Thought-action fusion: structure and specificity to OCD. J Obsessive Compuls Relat Disord 2014;3:39-45.

43. Abramowitz JS, Khandker M, Nelson CA, Deacon BJ, Rygwall R. The role of cognitive factors in the pathogenesis of obsessive-compulsive symptoms: a prospective study. Behav Res Ther 2006;44:1361-1374.

44. Shafran R, Rachman S. Thought-action fusion: a review. J Behav Ther Exp Psychiatry 2004;35:87-107.

45. Reuman L, Buchholz J, Abramowiz JS. Obsessive beliefs, experiential avoidance, and cognitive fusion as predictors of obsessive-compulsive disorder symptom dimensions. J Contextual Behav Sci 2018;9:15-20.

46. Viar MA, Bilsky SA, Armstrong T, Olatunji BO. Obsessive beliefs and dimensions of obsessive-compulsive disorder: an examination of specific associations. Cognit Ther Res 2011;35:108-117.

47. Wheaton MG, Abramowitz JS, Berman NC, Riemann BC, Hale LR. The relationship between obsessive beliefs and symptom dimensions in obsessive-compulsive disorder. Behav Res Ther 2010;48:949-954.

48. Hayes SC, Luoma JB, Bond FW, Masuda A, Lillis J. Acceptance and commitment therapy: model, processes and outcomes. Behav Res Ther 2006;44:1-25.

49. Lee SW, Cha H, Chung Y, Kim E, Song H, Chang Y, et al. The neural correlates of thought-action fusion in healthy adults: a functional magnetic resonance imaging study. Depress Anxiety 2019;36:732-743.

50. Lee SW, Song H, Jang T, Cha H, Kim E, Chang Y, et al. Aberrant functional connectivity of neural circuits associated with thought-action fusion in patients with obsessive-compulsive disorder. Psychol Med 2020;1-10. [Online ahead of print] 